\title{
High incidence and persistence of hepatitis $B$ virus infection in individuals receiving HIV care in KwaZulu-Natal, South Africa
}

\author{
Nokukhanya Msomi ${ }^{1 *+} \mathbb{D}$, Kogieleum Naidoo ${ }^{2,3+}$, Nonhlanhla Yende-Zuma ${ }^{2,3}$, Nesri Padayatchi ${ }^{2,3}$, \\ Kerusha Govender', Jerome Amir Singh ${ }^{2,4}$, Salim Abdool-Karim ${ }^{2,3,5}$, Quarraisha Abdool-Karim²,5 and Koleka Mlisana ${ }^{6}$
}

\begin{abstract}
Background: Hepatitis B virus (HBV), Human Immunodeficiency virus (HIV) and Tuberculosis (TB) are common infections in South Africa. We utilized the opportunity of care provision for HIV-TB co-infected patients to better understand the relationship between these coinfections, determine the magnitude of the problem, and identify risk factors for HBV infection in HIV infected patients with and without TB in KwaZulu-Natal, South Africa.

Methods: This retrospective cohort analysis was undertaken in 2018. In-care HIV infected patients were included in the analysis. Results from clinical records were analysed to determine the prevalence, incidence, persistence and factors associated with HBsAg positivity in HIV-infected patients with or without TB co-infection.

Results: A total of $4292 \mathrm{HIV}$-infected patients with a mean age of 34.7 years (SD: 8.8) were included. Based on HBsAg positivity, the prevalence of HBV was 8.5\% (363/4292) [95\% confidence interval (CI): 7.7-9.3] at baseline and 9.4\% (95\%Cl: 8.6-10.3\%) at end of follow-up. The HBV incidence rate was 2.1/100 person-years (p-y). Risk of incident HBV infection was two-fold higher among male patients (HR 2.11; 95\% Cl: 1.14-3.92), while severe immunosuppression was associated with a greater than two-fold higher risk of persistent infection (adjusted risk ratio (RR) $2.54 ; 95 \% \mathrm{Cl} 1.06-6.14 ; p=0.004$. Additionally, active TB at enrolment was associated with a two-fold higher risk of incident HBV infection (aHR 2.38; 95\% Cl: 0.77-7.35).

Conclusion: The provision of HIV care and treatment in high HBV burden settings provide a missed opportunity for HBV screening, immunization and care provision.
\end{abstract}

Keywords: HBV incidence, HIV/HBV coinfection, South Africa

\section{Background}

Human Immunodeficiency Virus (HIV) and Hepatitis B Virus (HBV) infections remain two of the major healthcare challenges in the twenty-first century. It is estimated that there were 257 million persons living with

\footnotetext{
*Correspondence: mdlalose@ukzn.ac.za

${ }^{+}$Nokukhanya Msomi and Kogieleum Naidoo contributed equally as first authors to this study and manuscript preparation.

'Discipline of Virology-University of KwaZulu-Natal, School of Laboratory Medicine and Medical Sciences and National Health Laboratory Service, Durban, South Africa

Full list of author information is available at the end of the article
}

chronic HBV infection globally (WHO 2017 global hepatitis report), making it the most common chronic viral infection worldwide [1]. In six WHO regions, global HBV surface antigen (HBsAg) sero-prevalence is reported to be $3,61 \%$ ( $95 \%$ CI 3.61-3.61) in the general population, with most countries in Africa shown to have higherintermediate endemicity (HBsAg prevalence 5-7.99\%), or highly endemic for HBV (HBsAg prevalence $\geq 8 \%$ ) [2]. Among the estimated 40 million people living with HIV globally, about $10 \%$ are concurrently chronically infected with HBV [3]. In sub-Saharan Africa, there is

(c) The Author(s). 2020 Open Access This article is licensed under a Creative Commons Attribution 4.0 International License, which permits use, sharing, adaptation, distribution and reproduction in any medium or format, as long as you give appropriate credit to the original author(s) and the source, provide a link to the Creative Commons licence, and indicate if changes were made. The images or other third party material in this article are included in the article's Creative Commons licence, unless indicated otherwise in a credit line to the material. If material is not included in the article's Creative Commons licence and your intended use is not permitted by statutory regulation or exceeds the permitted use, you will need to obtain permission directly from the copyright holder. To view a copy of this licence, visit http://creativecommons.org/licenses/by/4.0/ The Creative Commons Public Domain Dedication waiver (http://creativecommons.org/publicdomain/zero/1.0/) applies to the data made available in this article, unless otherwise stated in a credit line to the data. 
a syndemic of HIV, HBV and tuberculosis (TB). A syndemic is defined as a clustering of two or more disease epidemics that interact with each other increasing the magnitude of each epidemic [4].

The clinical disease spectrum of HIV, TB and HBV coinfection include hepatitis, either due to direct pathogen insult to the liver or as a complication of hepatotoxic drugs used to treat these infections. Some antiretroviral drugs commonly used in the treatment of HIV such as Tenofovir and Lamivudine, are also effectively used in the treatment of HBV. The pro-inflammatory state of chronic HIV infection drives the replication and evolution of pathogens [5] hence, upon HIV diagnosis, current standard of care recommends investigations to exclude commonly occurring infections like viral hepatitis and tuberculosis, especially in countries where these syndemics are prevalent. This also ensures that co-morbid infections are properly diagnosed and treated.

In HBV endemic areas like sub-Saharan Africa, most HBV infections occur perinatally and in early childhood, and both infections are more likely to progress to chronicity [6] in the absence of immunization. Amongst adults, HBV infection typically presents as acute hepatitis and progression to chronic HBV is estimated to be $<1 \%$ in immunocompetent individuals [7]. There is paucity of data on rates of incident HBV infection in adults. Furthermore, data on rates of persistence and/or clearance of HBV in the presence of HIV infection also remains scarce. Data from outside Africa indicate that the natural course of HBV infection is altered in the presence of HIV infection, showing higher levels of HBV viraemia, frequent episodes of reactivation and more rapid progression of liver fibrosis and hepatocellular carcinoma [8-10]. The EuroSida Swiss cohort study reported a significantly higher incidence of all-cause and liver-related mortalities in HBsAg-positive participants at 3.7 and $0.7 / 100$ person-years respectively, compared with HBsAg-negative participants (2.6/100 and $0.2 / 100$ person-years, respectively). Liver-related mortalities were three fold higher in HBsAg-positive subjects at $0.7 / 100$ person-years compared with HBsAg-negative subjects at $0.2 / 100$ person-years [11]. A nationwide study in Japan, a country with high HBV endemicity investigated risk factors for long term persistence of $\mathrm{HBV}$ in adults and concluded that genotype $\mathrm{A}$ is an independent risk factor for long term persistence of HBV [12]. Notably, genotype A has been shown to be the predominant circulating genotype in Africa [13]. Subic et al. highlight the barriers to the diagnosis and adequate treatment of $\mathrm{HBV}$ with estimation that only $10 \%$ of the 257 million people living with HBV have been diagnosed, and as few as $1 \%$ are being adequately treated [14].
Quantifying the burden and nature of HBV among TB-HIV co-infected South African patients accessing treatment and care services, is an important first step to enhance management of associated clinical complexities arising in the care of affected patients.

We conducted a retrospective chart review to assess the prevalence, incidence and persistence of HBV infection in HIV infected individuals accessing antiretroviral therapy in KZN, South Africa.

\section{Methods \\ Study design}

We undertook a retrospective chart review of HIV infected ART naïve adult patients enrolled in the PEPFAR funded CAPRISA AIDS Treatment Program (CAT) [15], and patients enrolled in the Starting Antiretroviral Therapy at Three Points in Tuberculosis (SAPiT) trial [16]. We analysed routine hepatitis B surface antigen (HBsAg) serology and other clinical data to determine baseline and overall prevalence of $\mathrm{HBV}$ during the follow up period, the number of new infections; the proportion of patients clearing infection or remaining with persisting HBV infection while being managed for HIV with or without tuberculosis.

\section{CAT cohort}

Patients in the CAT program were enrolled from two catchment populations in KwaZulu-Natal; a TB clinic in the urban eThekwini district of Durban and a rural primary health care clinic in the Vulindlela district. Patients were initiated on antiretroviral therapy (ART) in accordance with the 2004 eligibility criteria of the South African Government HIV/AIDS treatment guidelines [17]. Following ART initiation, clinical and adherence assessments were undertaken weekly for the first 2 weeks, then monthly for the first 6 months and every 3 months thereafter unless clinically indicated. Laboratory safety assessments, CD4+ cell count, and viral loads were conducted at baseline and every 6 months or as clinically indicated. The laboratory safety assessments included liver function tests and screening for $\mathrm{HBV}$ at baseline and 6-month intervals using Hepatitis B surface antigen ( $\mathrm{HBsAg}$ ) testing. Patients were regarded as lost to follow up (LTFU) if they missed three consecutive scheduled visits. No LTFU patients were re-enrolled.

\section{SAPiT cohort}

The SAPiT trial was conducted at the urban Centre for the AIDS Programme of Research (CAPRISA) eThekwini clinic. The CAPRISA eThekwini clinic adjoins the Prince Cyril Zulu Communicable Disease Centre, which is an outpatient TB facility. This was a 3-arm randomized open-label clinical trial in 642 
patients where the primary outcome of the trial was to determine the optimal timing of ART initiation in patients co-infected with HIV and TB. The study concluded that the initiation of antiretroviral therapy during tuberculosis therapy significantly improved survival and provides further impetus for the integration of tuberculosis and HIV services [18]. A secondary objective of this study was to compare IRIS risks and outcomes in patients initiating ART within a month of TB treatment initiation [19]. Laboratory safety assessments included screening for HBV at 6 months intervals.

\section{Laboratory methods}

HBsAg was used to screen for HBV as part of laboratory safety assessments at baseline and repeated at 6month intervals. The HBsAg tests were done on the Architect analyzer (Abbott Laboratories, WiesbadenGermany) from 2004 to 2010 and the ADVIA Centaur system (Siemens Healthcare Diagnostics, Tarrytown-NY USA) from 2011 to 2013 as per manufacturers' instructions. These immunoassays are registered for in vitro diagnostic use. HIV screening and confirmatory diagnosis was done by two rapid HIV tests and TB diagnosis was based on sputum smear positive for acid fast bacilli (AFB) by auramine and Ziel-Niehlsen stains. The TB and HIV diagnostic tests used have been previously described [18].

\section{Statistical analysis}

Wilcoxon rank sum test and Fisher's exact test were used to compute the association between gender, prevalent HBsAg positivity and other continuous and categorical baseline characteristics. The incidence of HBV and duration of follow-up among patients who tested HBsAg positive was calculated as time from the first HBsAg negative test date to the midpoint of last negative and first positive $\mathrm{HBsAg}$ test date. For patients who remained HBsAg negative, duration of follow-up was calculated as time from baseline HBsAg negative date to the last negative date. Univariable and multivariable proportional hazards regression was used to assess predictors of incident HBV infection. The Kaplan Meier method was used to calculate cumulative probability of $\mathrm{HBV}$ infection. Moreover, Poisson regression with robust variance was used to assess factors associated with HBV persistence. The following baseline variables were tested: age, gender TB comorbidity, the level of immunosuppression as determined by CD4+ count and body mass index. Statistical analyses were conducted using SAS version 9.4 (SAS Institute, Cary, North Carolina).

\section{Definitions for HBV prevalence, incidence, clearance and persistence}

The World Health Organization (WHO) guidelines for the prevention, care and treatment of persons with chronic HBV infection recommend that high-risk groups be screened for HBV infection by the detection of HBsAg. Chronic HBV infection is defined as persistence of HBsAg for more than 6 months.

We defined overall prevalence as the total number of patients with a positive HBsAg result at baseline and or during follow-up among all those tested. Each positive patient result was counted once.

Cumulative incidence was defined as the proportion of new HBsAg positive cases throughout the follow up period and this include cases with re-infection. The incidence rate was calculated per 100 person years.

Clearance was defined as a loss of HBsAg in those who were previously HBsAg positive and were followed up.

Persistence was defined as those patients whose result remained HBsAg positive with subsequent testing with no evidence of clearance.

During this study, ancillary care related to HBV infection and other diseases besides HIV or TB were managed according to prevailing South African standard clinical practice at the time (2005-2012), which did not include adult HBV immunization. Participants with symptomatic HBV disease were referred to public health sector facilities for further investigation and clinical management.

\section{Results}

Patient baseline characteristics

Four thousand two hundred and ninety two (4292) HIV infected patients were included in the analyses, of which 2681 (62.5\%) were women and 1611 (37.5\%) were men. Data on age, gender, clinical status are presented in Table 1 . There were statistically significant differences observed in all variables including age, TB status, body mass index, CD4 count and mean HIV viral load at enrolment along gender lines.

\section{HBV prevalence}

A total of 363 patients [8.5, 95\% confidence interval (CI): 7.7 to 9.3] were infected with HBV at baseline as determined by HBsAg seropositivity (Table 2). The proportion of patients from urban sites was $52.3 \%$ compared to $47.7 \%$ who were from rural settings. There was a higher baseline prevalence of $\mathrm{HBV}$ in urban sites compared with rural sites $(9.6 \%$ vs $7.2 \%$; RR: $95 \% \mathrm{CI} ; p=0.004)$. The proportion of HBV positivity at baseline was higher in men compared with women $(11.9 \%$ vs $6.4 \% p<0.001)$. A higher proportion of patients with a low BMI $(<18.5)$ were HBV positive at baseline compared with patients with a higher BMI $(11.6 \%$ vs $8.0 \% p=0.007)$. 
Table 1 Baseline clinical and demographic characteristics by gender

\begin{tabular}{|c|c|c|c|}
\hline Variable & Women $(N=2681)$ & Men $(N=1611)$ & $p$-value \\
\hline Research site, $\mathrm{n}(\%)$ & & & $<0.001$ \\
\hline Urban & $1271(47.4 \%)$ & $973(60.4 \%)$ & \\
\hline Rural & $1410(52.6 \%)$ & $638(39.6 \%)$ & \\
\hline Age group (years), $\mathrm{n}(\%)^{\mathrm{a}}$ & & & $<0.001$ \\
\hline$<24$ & $227(8.5 \%)$ & $48(3.0 \%)$ & \\
\hline 24-34 & $1412(52.8 \%)$ & $701(43.6 \%)$ & \\
\hline$\geq 35$ & $1036(38.7 \%)$ & $859(53.4 \%)$ & \\
\hline TB status at enrollment, $\mathrm{n}(\%)$ & & & $<0.001$ \\
\hline TB not present & $1910(71.2 \%)$ & $904(56.1 \%)$ & \\
\hline TB present & $771(28.8 \%)$ & $707(43.9 \%)$ & \\
\hline Body mass index $\left(\mathrm{kg} / \mathrm{m}^{2}\right), \mathrm{n}(\%)^{\mathrm{b}}$ & & & $<0.001$ \\
\hline$<18.5$ & $227(8.8 \%)$ & $301(19.3 \%)$ & \\
\hline$\geq 18.5$ & $2361(91.2 \%)$ & $1260(80.7 \%)$ & \\
\hline CD4 count at enrollment $\left(\right.$ cells $\left./ \mathrm{mm}^{3}\right), \mathrm{n}(\%)^{\mathrm{c}}$ & & & $<0.001$ \\
\hline$<50$ & $363(15.2 \%)$ & $336(22.9 \%)$ & \\
\hline $50-200$ & $1236(51.9 \%)$ & $777(52.9 \%)$ & \\
\hline$\geq 200$ & $782(32.8 \%)$ & $356(24.2 \%)$ & \\
\hline Viral load $\left(\log _{10}\right.$ copies $\left./ \mathrm{ml}\right)$, mean $\pm S D$ & $4.9 \pm 0.9$ & $5.1 \pm 0.8$ & $<0.001$ \\
\hline
\end{tabular}

a 9 patients had missing data

b 143 patients had missing data

c 442 patients had missing data

Table 2 Baseline Clinical and Demographic Characteristics by HBsAg Status

\begin{tabular}{|c|c|c|c|}
\hline Variable & $\begin{array}{l}\text { HBsAg Positive } \\
(N=363)\end{array}$ & HBsAg Negative $(N=3929)$ & $p$-value \\
\hline Research site, $\mathrm{n}(\%)$ & & & 0.004 \\
\hline Urban & $216(9.6 \%)$ & $2028(90.4 \%)$ & \\
\hline Rural & $147(7.2 \%)$ & $1901(92.8 \%)$ & \\
\hline Gender, $\mathrm{n}(\%)$ & & & $<.001$ \\
\hline Male & $192(11.9 \%)$ & $1419(88.1 \%)$ & \\
\hline Female & $171(6.4 \%)$ & $2510(93.6 \%)$ & \\
\hline Age group (years), $\mathrm{n}(\%)^{\mathrm{a}}$ & & & 0.403 \\
\hline$<24$ & $22(8.0 \%)$ & $253(92.0 \%)$ & \\
\hline $24-34$ & $191(9.0 \%)$ & $1922(91.0 \%)$ & \\
\hline$\geq 35$ & $149(7.9 \%)$ & $1746(92.1 \%)$ & \\
\hline TB status at enrollment, $\mathrm{n}(\%)$ & & & 0.564 \\
\hline TB not present & $233(8.3 \%)$ & $2581(91.7 \%)$ & \\
\hline TB present & $130(8.8 \%)$ & $1348(91.2 \%)$ & \\
\hline Body mass index $\left(\mathrm{kg} / \mathrm{m}^{2}\right), \mathrm{n}(\%)^{\mathrm{b}}$ & & & 0.007 \\
\hline$<18.5$ & $61(11.6 \%)$ & $467(88.4 \%)$ & \\
\hline$\geq 18.5$ & $288(8.0 \%)$ & $3333(92.0 \%)$ & \\
\hline $\mathrm{CD} 4+$ count at enrollment $\left(\mathrm{cell} / \mathrm{s} / \mathrm{mm}^{3}\right), \mathrm{n}(\%)^{\mathrm{c}}$ & & & 0.185 \\
\hline$<50$ & $74(10.6 \%)$ & $625(89.4 \%)$ & \\
\hline $50-200$ & $173(8.6 \%)$ & $1840(91.4 \%)$ & \\
\hline$\geq 200$ & 93 (8.2\%) & 1045 (91.8\%) & \\
\hline HIV Viral load ( $\log _{10}$ copies/ml), mean (SD) & $5.0(0.9)$ & $5.0(0.9)$ & 0.179 \\
\hline
\end{tabular}

a 9 patients had missing data

b 143 patients had missing data

c 453 patients had missing data 
The presence of tuberculosis at enrolment, level of immunosuppression and baseline mean HIV viral load were not associated with $\mathrm{HBsAg}$ seropositivity at baseline (Table 2).

Data on incidence rates, persistence and clearance in relation to baseline prevalence are presented in Fig. 1 flowchart. A total of 1016 of the 4292 patients (23.7\%) had subsequent HBsAg results. These patients had follow-up results for up to 5 years and were included in the analysis for incidence, clearance and persistence as outlined in Fig. 1. The overall prevalence of $\mathrm{HBV}$ at the end of the follow up period was 9.4\% (95\% CI: 8.6 to $10.3 \%$ ).

\section{HBV incidence rates}

Data on incident HBV infections are presented in Table 3. Among the 913 patients who were HBsAg negative at baseline with follow-up results, we identified 41 incident HBV infections occurring over 1920 person years (p-y) yielding an overall HBV incidence rate of 2.1/ 100 p-y. Male gender was associated with a two-fold higher risk of having incident HBV infection [HR 2.11; 95\% CI: $1.14-3.92 p=0.017$ ], while not statistically significant in the multivariable analyses, [aHR 1.72; 95\% CI 0.89-3.35 $p=0.108$ ] this may be of clinical relevance. Other factors associated with incident HBV infection including patients from a rural site and patients with TB at baseline are summarized in Table 3.

Despite the small numbers of patients tested over time, and the reduced numbers in follow-up, the Kaplan-Meier curve in Fig. 2, demonstrates a steady cumulative increase in the probability of incident HBV infection over the first 2 years of follow-up.

\section{Clearance}

Of the 41 incident HBV infections, 17(41.5\%) subsequently cleared the infection whereas 24 (58.5\%) did not have any evidence of clearance as shown by presence of HBsAg.

Among the 56/103 (54.4\%) patients who cleared HBV infection during follow-up (95\% CI: 44.8 to 63.7), nine (16\%) were re-infected and 47(83.9\%) did not demonstrate evidence of reinfection at last follow-up visit.

\section{Persistence}

Data on persistent $\mathrm{HBV}$ infection are presented in Table 4. There were 103 patients who were HBsAg positive at baseline with follow-up results and 47 (45.6\%; 95\% CI: 36.3 to 55.2 ) had persistent HBsAg positivity during follow-up. Predictors of persistent infection included severe immunosuppression where CD4 cell count below 50 cells/uL was associated with a higher risk of developing persistent infection compared to CD4 cell count $>200$ cells/uL [adjusted risk ratio (RR) 2.54; $95 \%$ CI $1.06-6.14 ; p=0.004]$.

\section{Discussion}

We report alarmingly high prevalence rates of $\mathrm{HBV}$ infection based on HBsAg positivity in HIV infected patients seeking treatment and care services in South Africa. While these rates are consistent with data reported in other settings in sub-Saharan Africa, this confirms that South Africa remains endemic for HBV, HIV as well as tuberculosis [20]. Notwithstanding higher rates of ARV treatment initiation rates in women compared to men in our cohorts, baseline HBV prevalence was almost two times higher in men compared to women (11.9\% vs $6.4 \%)$, consistent with findings from settings where heterosexual transmission is dominant. The high HBV prevalence rates among men in our general HIV population is comparable to $\mathrm{HBV}$ prevalence rates observed among high risk men having sex with men (MSM) populations where $\mathrm{HBV}$ prevalence rates of $>8$

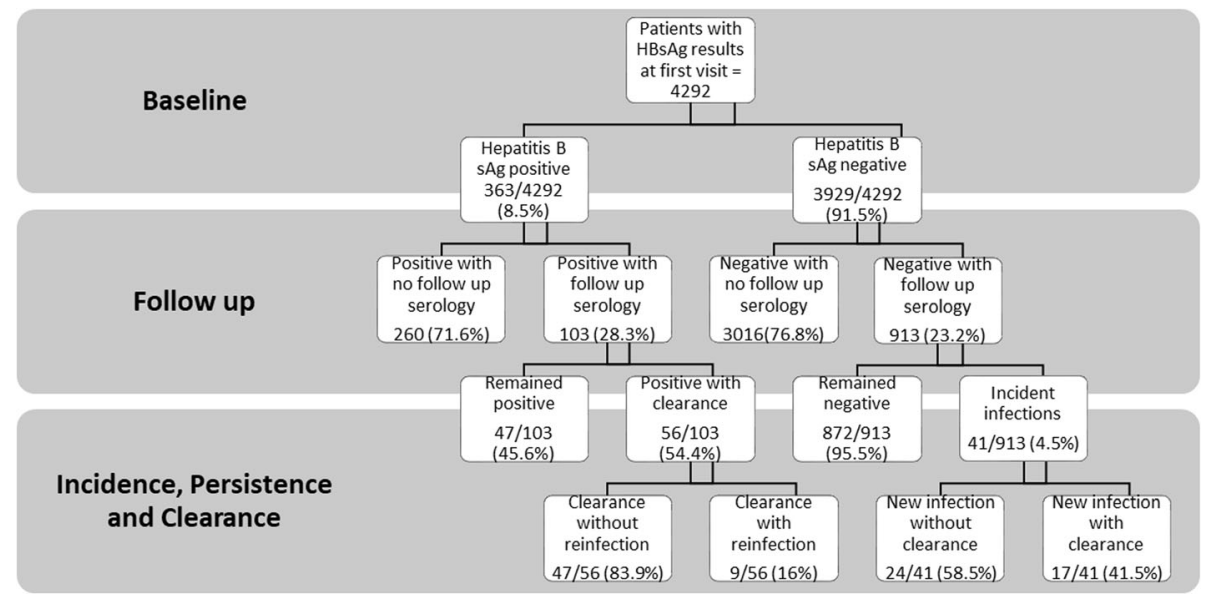

Fig. 1 Flowchart depicting prevalence, incidence, clearance and persistence of HBV among HIV infected patients 
Table 3 Factors associated with incident HBV infection

\begin{tabular}{|c|c|c|c|c|}
\hline Baseline characteristics & HR $(95 \% \mathrm{Cl})$ & $p$-value & aHR $(95 \% \mathrm{Cl})$ & $p$-value \\
\hline \multicolumn{5}{|l|}{ Gender (ref: female) } \\
\hline Male & $2.11(1.14-3.92)$ & 0.017 & $1.72(0.89-3.35)$ & 0.108 \\
\hline \multicolumn{5}{|l|}{ Research site (ref: urban) } \\
\hline Rural & $1.14(0.50-2.59)$ & 0.758 & $3.04(0.82-11.21)$ & 0.095 \\
\hline \multicolumn{5}{|l|}{ Age group (years) (ref: $\geq 35$ ) } \\
\hline$<24$ & $1.12(0.33-3.83)$ & 0.853 & $1.01(0.23-4.50)$ & 0.985 \\
\hline $24-34$ & $1.13(0.59-2.13)$ & 0.716 & $1.20(0.62-2.33)$ & 0.593 \\
\hline \multicolumn{5}{|c|}{ CD4 count (cells/mm³) (ref: $\geq 200)$} \\
\hline$<50$ & $1.35(0.53-3.39)$ & 0.528 & $1.33(0.52-3.39)$ & 0.550 \\
\hline $50-200$ & $1.09(0.50-2.39)$ & 0.832 & $1.18(0.53-2.63)$ & 0.693 \\
\hline \multicolumn{5}{|c|}{ Active TB at enrolment (ref: no) } \\
\hline Yes & $1.57(0.79-3.13)$ & 0.203 & $2.38(0.77-7.35)$ & 0.132 \\
\hline \multicolumn{5}{|l|}{ BMI $\left(\mathrm{kg} / \mathrm{m}^{2}\right)($ ref: $<18.5)$} \\
\hline$\geq 18.5$ & $0.84(0.35-1.99)$ & 0.687 & $1.21(0.46-3.16)$ & 0.703 \\
\hline
\end{tabular}

and $11 \%$ were observed in China and the United States of America [21] [22], respectively. The baseline prevalence of HBV was similar in all age groups, suggesting that our study patients did not benefit from the routine immunization against HBV that was rolled out to infants and newborns in South Africa in 1995.
The high HBV incidence rates in our setting is also deeply concerning. Incidence rates in our cohorts are about four fold higher than rates observed among ART accessing populations in Uganda $(0.49 / 100$ p-y [23] vs $2.1 / 100 \mathrm{p}-\mathrm{y}$ ), despite more than $90 \%$ of our patients receiving either lamivudine or a combination of Tenofovir

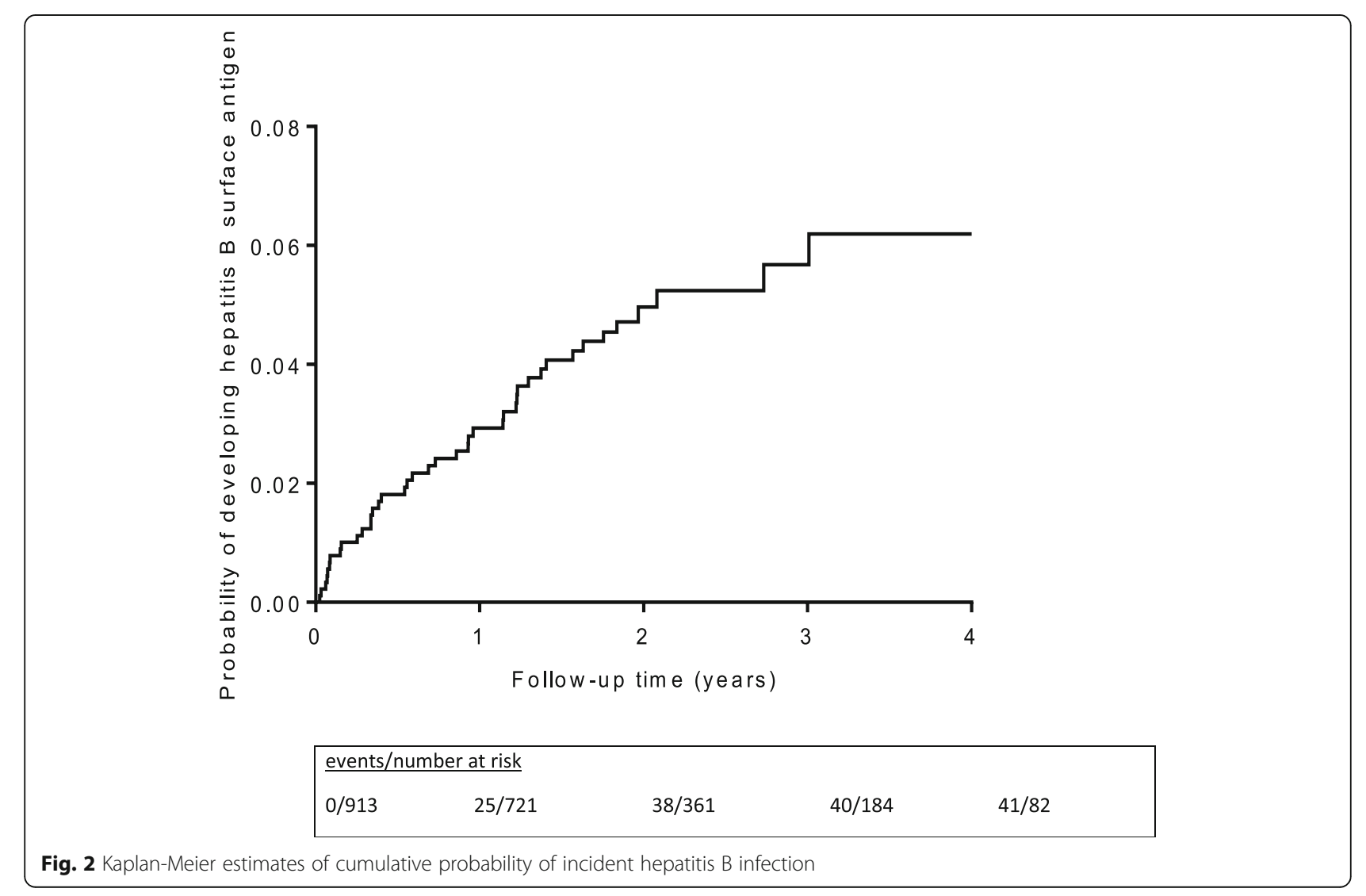


Table 4 Factors associated with persistent HBV infection

\begin{tabular}{|c|c|c|c|c|}
\hline Baseline characteristics & RR $(95 \% \mathrm{Cl})$ & $p$-value & aRR $(95 \% \mathrm{Cl})$ & $p$-value \\
\hline \multicolumn{5}{|l|}{ Gender (ref: female) } \\
\hline Male & $1.75(1.00-3.06)$ & 0.05 & $1.71(0.97-3.02)$ & 0.064 \\
\hline \multicolumn{5}{|l|}{ Research site (ref: urban) } \\
\hline Rural & $0.59(0.24-1.47)$ & 0.254 & $0.51(0.17-1.52)$ & 0.226 \\
\hline \multicolumn{5}{|l|}{ Age group (years) (ref: $\geq 35$ ) } \\
\hline$<24$ & $1.46(0.51-4.20)$ & 0.478 & $1.57(0.47-5.23)$ & 0.463 \\
\hline $24-34$ & $1.24(0.69-2.25)$ & 0.469 & $1.43(0.79-2.61)$ & 0.241 \\
\hline \multicolumn{5}{|c|}{ CD4 count (cells/mm³) (ref: $\geq 200)$} \\
\hline$<50$ & $2.63(1.10-6.32)$ & 0.030 & $2.54(1.06-6.14)$ & 0.038 \\
\hline $50-200$ & $1.57(0.68-3.58)$ & 0.289 & $1.54(0.65-3.63)$ & 0.327 \\
\hline \multicolumn{5}{|c|}{ Active TB at enrolment (ref: no) } \\
\hline Yes & $1.17(0.66-2.10)$ & 0.588 & $0.80(0.42-1.52)$ & 0.498 \\
\hline \multicolumn{5}{|l|}{ BMI $\left(\mathrm{kg} / \mathrm{m}^{2}\right)($ ref: $<18.5)$} \\
\hline$\geq 18.5$ & $1.15(0.46-2.85)$ & 0.764 & $1.33(0.54-3.28)$ & 0.538 \\
\hline
\end{tabular}

and lamivudine first line ART regimens. This suggests there is ongoing transmission and acquisition of HBV in ART treated adults and should prompt future surveillance studies on HBV drug resistance in the South African setting.

The high cumulative incidence and cumulative probability of incident HBV infection underscores the missed opportunity of identifying patients susceptible to HBV and the provision of early vaccination to prevent new infections. Similarly, the high rates of re-infection among patients that initially clear incident infections indicate a high background burden of disease, high HBV transmission rates as well as high rates of unprotected sex among HIV infected patients. This emphasizes the need for comprehensive prevention services within HIV care programmes that includes routine HBV vaccination to all HIV infected patients, provision of condoms coupled with, health promotion education that includes correct condom use, and risk reduction counselling to this audience. The high rate of HBV re-infection also suggests that patients with HIV co-infection on ART may not be developing sufficient protective immunity following natural exposure to HBV infection, suggesting persistently inadequate functional immunity in these patients [24, 25]. There is also growing evidence that HIV infected patients have suboptimal antibody responses to HBV vaccine in both infants and adults, with some studies recommending reinforced or accelerated vaccination in HIV co-infected patients [26, 27].

Our study found that men had a significantly higher prevalence of HBV at baseline and had a higher risk of incident as well as persistent HBV infection. This finding is in keeping with data from Asian patients, where male gender was identified as an independent negative prognosticator for chronic HBV infection and its complications [28]. HBV prevalence was also found to be more common among males than females $(15.4 \%$ vs $10.1 \%, p=0.001$ ), within a cohort of HIV infected patients enrolled between 2004 and 2007 in Nigeria [29]. Data from an older American cohort study in patients receiving haemodialysis showed evidence of a sex difference in response to hepatitis B virus, probably explaining the greater incidence of several chronic liver diseases, including primary hepatocellular carcinoma, in males [30]. The role of gender needs to be investigated with further studies.

The presence of TB at baseline was associated with a 2fold increased risk of incident HBV infection, suggesting that HIV, TB and HBV co-infection may drive each other creating a syndemic. Advanced immunosuppression as evidenced by CD4 count $<200$ cells $/ \mathrm{mm}^{3}$ was not associated with incident $\mathrm{HBV}$ infection or higher prevalence of $\mathrm{HBV}$ at baseline. This finding is similar to other cohorts where baseline CD4 count was not significantly different between HBV infected and HBV uninfected groups [11, 31, 32]. However, the risk of persistent HBV infection was found to be higher with severe immunosuppression, demonstrating the importance of immune-competence in clearing HBV infection. The data suggest that HIV confers a risk for HBV persistence, hence the need for targeted prevention in this high-risk group. The role of adaptive anti-HBV responses in the control of HBV has been reviewed elsewhere [33].

The limitation in our retrospective study is not analyzing the effect of different ART drug regimens on the incidence and persistence of HBV in HIV co-infected patients. All ART regimens that patients received would have included lamivudine and introduced Tenofovir in the latter part of 2013 as HBV active ART. The Ugandan 
study by Seremba et al, did not find any new infections in patients receiving Tenofovir based ART, while some new infections occurred with Lamivudine-only based ART [23].

Not all patients had longitudinal follow up, and the smaller number of patients in follow up is a limitation and may have resulted in the underestimation of the true burden of disease. Other testing limitations include not determining HBV surface antibodies at baseline and not testing for HBV core antibodies at any time during follow up.

With the presence of an effective vaccine against HBV, HIV and TB have overshadowed its prominence as a significant infectious disease over the past 3 decades. There is however a renewed realization that the burden of HBV continues to increase in the post-vaccination era [2].

High HBV prevalence, incidence and re-infection rates pose a serious public health threat from ongoing HBV transmission as well as from enhancing HIV-infected patients' risk to non-AIDS comorbidities such as cirrhosis and hepatocellular carcinoma. These data highlight the vulnerability of the South African population to infectious disease syndemics that include HBV, HIV, TB, and the ongoing morbidity and mortality, associated with these conditions. These co-occurring conditions intertwined with similar biologic, social and environmental drivers, are likely to foster emergence of other epidemics in the future. An urgent appraisal of how the public health system and communities are better able to identify and respond to these epidemics, in order to mitigate their impact is warranted. We illustrate ongoing acquisition of HBV in adult patients receiving HIV care, and suggest that expanding the rollout of HBV vaccination and integrating it as part of comprehensive HIV care in countries where HBV is endemic, is the first step in a wholistic response to the HIV-HBV-TB syndemics. While widespread ART access offers promising viral suppression in HBV-HIV co-infected individuals, this strategy is not a route to global eradication of HBV and HIV. Additional investment and resources aimed at improving routine diagnostic screening while reducing the number of undiagnosed cases, development of curative therapy, and improvements in vaccine and drug coverage, would be appropriate responses to the call by the World Health Assembly, towards the global elimination of HBV as a public health threat by 2030 [34].

\section{Conclusion}

This work demonstrated a high incidence of HBV infection in patients receiving care for HIV and TB in South Africa. We conclude that provision of HIV care and treatment in high HBV burden settings provide a missed opportunity for HBV screening, immunization and care provision.

\section{Abbreviations}

HBV: Hepatitis B virus; HBsAg: Hepatitis B surface antigen; TB: Tuberculosis; ART: Antiretroviral treatment; HIV: Human immunodeficiency virus; SD: Standard deviation; HR: Hazard-ratio; aHR: Adjusted hazard ratio; BMI: Body mass index; LTFU: Loss to follow-up

\section{Acknowledgements}

An overview of the results was presented at the Conference on Retroviruses and Opportunistic Infections, 2020, Boston, Massachusetts. We thank the patients for their participation in these projects. We also thank all members of the SAPIT study team and the CAPRISA AIDS treatment programme for their dedication and commitment.

\section{Authors' contributions}

NM and KN were responsible for study conceptualization, design and manuscript preparation. NM, KG and NYZ contributed to the analysis and interpretation of data. NP, KN and NYZ were responsible for acquisition of data and maintenance of database. JAS, SAK and QAK contributed to the critical revision of the manuscript and intellectual input. KM provided supervision and manuscript review. All authors contributed to manuscript revision and approved the submitted version.

\section{Funding}

The U.S. President's Emergency Plan supported this work for AIDS Relief; the Centre for the AIDS Programme of Research in South Africa (CAPRISA); the Global Fund to Fight AIDS, Tuberculosis, and Malaria; and the National Institutes of Health Comprehensive International Program of Research on AIDS.

\section{Availability of data and materials}

The datasets used and/or analysed during the current study are available from the corresponding author on reasonable request.

\section{Ethics approval and consent to participate}

Approval for the retrospective chart review and analysis was obtained from the University of KwaZulu-Natal, Biomedical Research Ethics Committee (Ref E248/05).

Patients enrolled in the SAPIT study provided written informed consent for participation in future studies including use of their medical records. The University of KwaZulu-Natal, Biomedical Research Ethics Committee and the Medicines Control Council of South Africa approved the SAPiT study (Ref E107/05 and 20060157).

\section{Consent for publication \\ Not applicable.}

\section{Competing interests}

None declared.

\section{Author details}

${ }^{1}$ Discipline of Virology-University of KwaZulu-Natal, School of Laboratory Medicine and Medical Sciences and National Health Laboratory Service, Durban, South Africa. ${ }^{2}$ Centre for the AIDS Programme of Research in South Africa, University of KwaZulu-Natal, Durban, South Africa. ${ }^{3} \mathrm{MRC}$-CAPRISA HIV-TB Pathogenesis and Treatment Research Unit, Doris Duke Medical Research Institute, University of KwaZulu-Natal, Durban, South Africa. ${ }^{4}$ Dalla Lana School of Public Health, University of Toronto, Toronto, Canada. ${ }^{5}$ Department of Epidemiology, Mailman School of Public Health, Columbia University, New York, USA. ${ }^{6}$ National Health Laboratory Service and School of Laboratory Medicine and Medical Sciences, University of KwaZulu-Natal,

Durban, South Africa.

Received: 27 August 2020 Accepted: 31 October 2020

Published online: 16 November 2020

\section{References}

1. Global Hepatitis Report 2017. Geneva: World Health Organization; 2017.

2. Schweitzer A, Horn J, Mikolajczyk RT, Krause G, Ott JJ. Estimations of worldwide prevalence of chronic hepatitis $B$ virus infection: a systematic review of data published between 1965 and 2013. Lancet. 2015;386(10003): $1546-55$. 
3. Phung B-C, Sogni P, Launay O. Hepatitis B and human immunodeficiency virus co-infection. World J Gastroenterol: WJG. 2014; 20(46):17360.

4. Tsai AC, Mendenhall E, Trostle JA, Kawachi I. Co-occurring epidemics, syndemics, and population health. Lancet. 2017;389(10072):978-82.

5. Lisco A, Vanpouille C, Margolis L. War and peace between microbes: HIV-1 interactions with coinfecting viruses. Cell Host Microbe. 2009;6(5):403-8.

6. Shepard CW, Simard EP, Finelli L, Fiore AE, Bell BP. Hepatitis B virus infection: epidemiology and vaccination. Epidemiol Rev. 2006;28(1):112-25.

7. Sherlock S. The natural history of hepatitis B. Postgrad Med J. 1987;63(Suppl 2):7-11.

8. Puoti M, Torti C, Bruno R, Filice G, Carosi G. Natural history of chronic hepatitis B in co-infected patients. J Hepatol. 2006;44:S65-70.

9. Kew MC. Hepatitis B virus/human immunodeficiency virus co-infection and its hepatocarcinogenic potential in Sub-Saharan Black Africans. Hepat Mon. 2012;12(10 HCC)

10. Chun HM, Roediger MP, Hullsiek KH, Thio CL, Agan BK, Bradley WP, et al. Hepatitis B virus coinfection negatively impacts HIV outcomes in HIV seroconverters. J Infect Dis. 2011;205(2):185-93.

11. Konopnicki D, Mocroft A, De Wit S, Antunes F, Ledergerber B, Katlama C, et al. Hepatitis B and HIV: prevalence, AIDS progression, response to highly active antiretroviral therapy and increased mortality in the EuroSIDA cohort. Aids. 2005;19(6):593-601

12. Ito K, Yotsuyanagi $H$, Yatsuhashi $H$, Karino $Y$, Takikawa $Y$, Saito T, et al. Risk factors for long-term persistence of serum hepatitis B surface antigen following acute hepatitis B virus infection in Japanese adults. Hepatology. 2014;59(1):89-97.

13. Kramvis A. Molecular characteristics and clinical relevance of African genotypes and subgenotypes of hepatitis B virus. South African medical journal =. Suid-Afrikaanse tydskrif vir geneeskunde. 2018;108(8b):17-21.

14. Subic M, Zoulim F. How to improve access to therapy in hepatitis B patients. Liver Int. 2018;38(S1):115-21.

15. Naidoo K, Hassan-Moosa R, Yende-Zuma N, Govender D, Padayatchi N, Dawood $\mathrm{H}$, et al. High mortality rates in men initiated on anti-retroviral treatment in KwaZulu-Natal, South Africa. PloS one. 2017;12(9):e0184124.

16. Abdool Karim SS, Naidoo K, Grobler A, Padayatchi N, Baxter C, Gray AL, et al. Integration of antiretroviral therapy with tuberculosis treatment. N Engl J Med. 2011;365(16):1492-501.

17. Department of Health, South Africa: Operational Plan for Comprehensive HIV and AIDS care, management and treatment for South Africa.https:// www.gov.za/sites/default/files/gcis_document/201409/aidsoperationalplan1 0.pdf. Accessed 06 Nov 2020

18. Abdool Karim SS, Naidoo K, Grobler A, Padayatchi N, Baxter C, Gray A, et al. Timing of initiation of antiretroviral drugs during tuberculosis therapy. $\mathrm{N}$ Engl J Med. 2010;362(8):697-706.

19. Naidoo K, Yende-Zuma N, Padayatchi N, Naidoo K, Jithoo N, Nair G, et al. The immune reconstitution inflammatory syndrome after antiretroviral therapy initiation in patients with tuberculosis: findings from the SAPIT trial. Ann Intern Med. 2012;157(5):313-24.

20. Lavanchy D. Worldwide epidemiology of HBV infection, disease burden, and vaccine prevention. J Clin Virol. 2005;34:S1-3.

21. Ma X, Zhang $Q$, He X, Sun W, Yue H, Chen S, et al. Trends in prevalence of HIV, syphilis, hepatitis $C$, hepatitis $B$, and sexual risk behavior among men who have sex with men: results of 3 consecutive respondent-driven sampling surveys in Beijing, 2004 through 2006. J Acquir Immune Defic Syndr. 2007;45(5):581-7.

22. Mackellar DA, Valleroy LA, Secura GM, McFarland W, Shehan D, Ford W et al. Two decades after vaccine license: hepatitis B immunization and infection among young men who have sex with men. Am J Public Health. 2001;91(6):965

23. Seremba E, Ssempijja V, Kalibbala S, Gray RH, Wawer MJ, Nalugoda F, et al. Hepatitis B incidence and prevention with antiretroviral therapy among HIVpositive individuals in Uganda. Aids. 2017;31(6):781-6.

24. Okulicz JF, Le TD, Agan BK, Camargo JF, Landrum ML, Wright E, et al. Influence of the timing of antiretroviral therapy on the potential for normalization of immune status in human immunodeficiency virus 1infected individuals. JAMA Intern Med. 2015;175(1):88-99.

25. Lazizi Y, Keros LG, Delfraissy J-F, Boue F, Dubreuil P, Badur S, et al. Reappearance of hepatitis $B$ virus in immune patients infected with the human immunodeficiency virus type 1. J Infect Dis. 1988;158(3):666-7.
26. Simani OE, Leroux-Roels G, François G, Burnett RJ, Meheus A, Mphahlele MJ. Reduced detection and levels of protective antibodies to hepatitis B vaccine in under 2-year-old HIV positive south African children at a paediatric outpatient clinic. Vaccine. 2009;27(1):146-51.

27. Neukam K, Gutiérrez-Valencia A, Llaves-Flores S, Espinosa N, Viciana P, López-Cortés LF. Response to a reinforced hepatitis B vaccination scheme in HIV-infected patients under real-life conditions: Vaccine; 2019.

28. Yuen MF, Yuan HJ, Wong DK, Yuen JC, Wong WM, Chan AO, Wong BC, Lai KC, Lai CL. Prognostic determinants for chronic hepatitis B in Asians: therapeutic implications. Gut. 2005;54(11):1610-4.

29. Otegbayo JA, Taiwo BO, Akingbola TS, Odaibo GN, Adedapo KS, Penugonda $S$, et al. Prevalence of hepatitis $B$ and $C$ seropositivity in a Nigerian cohort of HIV-infected patients. Ann Hepatol. 2008;7(2):152-6.

30. London WT, Drew JS. Sex differences in response to hepatitis B infection among patients receiving chronic dialysis treatment. Proc Natl Acad Sci. 1977;74(6):2561-3.

31. Thio CL, Seaberg EC, Skolasky R Jr, Phair J, Visscher B, Muñoz A, et al. HIV-1, hepatitis B virus, and risk of liver-related mortality in the multicenter cohort study (MACS). Lancet. 2002;360(9349):1921-6.

32. Sheng $W-H$, Chen M-Y, Hsieh S-M, Hsiao C-F, Wang J-T, Hung C-C, et al. Impact of chronic hepatitis B virus (HBV) infection on outcomes of patients infected with HIV in an area where HBV infection is hyperendemic. Clin Infect Dis. 2004;38(10):1471-7.

33. Loggi E, Gamal N, Bihl F, Bernardi M, Andreone P. Adaptive response in hepatitis B virus infection. J Viral Hepat. 2014;21(5):305-13.

34. Organization $\mathrm{WH}$. Combating hepatitis $\mathrm{B}$ and $\mathrm{C}$ to reach elimination by 2030: advocacy brief. 2016

\section{Publisher's Note}

Springer Nature remains neutral with regard to jurisdictional claims in published maps and institutional affiliations.

\section{Ready to submit your research? Choose BMC and benefit from:}

- fast, convenient online submission

- thorough peer review by experienced researchers in your field

- rapid publication on acceptance

- support for research data, including large and complex data types

- gold Open Access which fosters wider collaboration and increased citations

- maximum visibility for your research: over $100 \mathrm{M}$ website views per year

At BMC, research is always in progress.

Learn more biomedcentral.com/submissions 